\title{
Effect of adrenalectomy on the development of a pancreatic islet lesion in fa/fa rats
}

\author{
M.T. Kibenge, C. B. Chan \\ Department of Anatomy and Physiology, Atlantic Veterinary College, University of Prince Edward Island, Charlottetown, \\ Prince Edward Island, Canada
}

Summary Adrenalectomy prevents development of obesity and hyperinsulinaemia in obese $(f a / f a)$ Zucker rats, thereby implicating the hypothalamopituitary-adrenal axis in the pathogenesis of obesity. In this study glucose-induced insulin secretion and glucokinase activity were investigated in isolated islets from adrenalectomized and control obese and lean female rats. Islets from control $f a / f a$ rats were more sensitive to glucose with a half-maximal effective concentration $\left(\mathrm{EC}_{50}\right)$ of $6.1 \pm 2.0 \mathrm{mmol} \cdot \mathrm{l}^{-1} \mathrm{com}$ pared with $10.6 \pm 2.7 \mathrm{mmol} \cdot \mathrm{l}^{-1}$ for adrenalectomized $\mathrm{fa} / \mathrm{fa}$ rat islets. Adrenalectomy did not alter the islet sensitivity to glucose in the lean rats $\left(\mathrm{EC}_{50}\right.$ of $9.4 \pm 1.5 \mathrm{mmol} \cdot 1^{-1}$ and $9.3 \pm 2.0 \mathrm{mmol} \cdot 1^{-1}$ for adrenalectomized and control lean rats respectively). Mannoheptulose did not inhibit insulin secretion from control obese rats; however at concentrations of $1.0 \mathrm{mmol} \cdot \mathrm{I}^{-1}$ or more it significantly inhibited glucose-induced insulin secretion in adrenalectomized obese and lean, and control lean rat islets $(p<0.05)$.
In adrenalectomized $f a / f a$ islets the glucokinase $\mathrm{K}_{\mathrm{m}}$ was increased twofold compared with the control $f a / f a$ rats $\left(9.5 \pm 1.5 \mathrm{mmol} \cdot \mathrm{l}^{-1}\right.$ vs $5.0 \pm 1.5 \mathrm{mmol} \cdot \mathrm{l}^{-1}$, respectively), but there was no significant change in glucokinase $\mathrm{K}_{\mathrm{m}}$ in the lean rat islets after adrenalectomy. Mannoheptulose $\left(10 \mathrm{mmol} \cdot \mathrm{l}^{-1}\right)$ caused a significant reduction in glucose phosphorylation in disrupted islets of adrenalectomized $f a / f a$ and lean, and of control lean rats, but not of control $f a / f a$ rats. These data demonstrate that development of abnormal regulation of glycolysis in pancreatic islet beta cells of $\mathrm{fa}$ / $f a$ rats, as indicated by the insulin response to mannoheptulose and glucokinase activity, is dependent on an intact hypothalamo-pituitary-adrenal axis. [Diabetologia (1996) 39: 190-198]

Key words Insulin secretion, mannoheptulose, adrenalectomy, glucokinase, hypothalamo-pituitary-adrenal axis, islets of Langerhans.
Hyperinsulinaemia is a characteristic of human obesity and the genetically transmitted obesity syndromes of animal rodent models including the Zucker $f a / f a$ rat [1]. The actual causes of hyperinsulinaemia in $f a /$ $f a$ rats are not yet known; however, weaning to a

Received: 12 June 1995 and in revised form: 25 August 1995

Corresponding author: Dr. C. Chan, Department of Anatomy and Physiology, University of Prince Edward Island, 550 University Avenue, Charlottetown, PEI, C1A 4P3, Canada Abbreviations: ADX, Adrenalectomy/adrenalectomized; $\mathrm{CRH}$, corticotrophin releasing hormone; DMEM, Dulbecco's modified Eagle's medium; $\mathrm{EC}_{50}$; half-maximal effective concentration; HPA, hypothalamo-pituitary-adrenal; MH, mannoheptulose; Hepes, 4-(2-hydroxyethyl)-1-piperazineethane sulphonic acid. high-carbohydrate diet plays a significant role in the development of obesity and hyperinsulinaemia in these rats [2]. Increased sensitivity to glucose of the pancreatic beta cells of $f a / f a$ rats in both the preobese [3-5] and adult stages [6-9] is observed. This increased response of $\mathrm{fa} / \mathrm{fa}$ rats to glucose stimulation might be related to changes in the primary glucose sensing mechanisms of the pancreatic islet beta cells because sensitivity to other stimulants is not different from that observed in lean rats [9].

Glucokinase, for which there is growing evidence as the primary pancreatic beta-cell glucose sensor [10], is reported to have increased sensitivity to glucose in $f a / f a$ rat isolated islets [11]. The activity of glucokinase in pancreatic beta cells is regulated by glu- 
cose, increasing at high glucose levels and decreasing at low glucose levels both in vivo [12] and in vitro $[13,14]$. Failure of the insulin response to adapt to changes in ambient glucose is reported in starved adult $f a / f a$ rats in vitro [9] and in vivo [15]. Furthermore, $f a / f a$ rats exhibit fasting hyperinsulinaemia despite having blood glucose levels similar to lean rats [6]. Mannoheptulose (MH), which competitively inhibits glucokinase to block glucose-induced insulin release [16], is found to have a reduced effect on insulin secretion in isolated islets from adult and weanling $f a / f a$ rats $[9,17]$, a phenomenon also reported in other genetically obese rodents, including corpulent $(c p / c p)$ rats [18]. These changes in insulin secretory regulation may reflect early defects in pancreatic islet glucokinase function.

Adrenalectomy (ADX), when performed before weaning, prevents development of all hormonal, metabolic and behavioural abnormalities including hyperinsulinaemia in $f a / f a$ rats $[19,20]$ and these same abnormalities are partially reduced when ADX is carried out in adult rats $[21,22]$. The effects of ADX are reversed by glucocorticoid replacement [20, 22]. The mechanism by which ADX normalizes or reduces insulin secretion is still not clear; however, reduced food intake $[21,23]$, or removal of the inhibitory effect of corticosterone on the autonomic nervous system activity to the endocrine pancreas [20] may both play crucial roles. We considered that ADX might prevent hyperinsulinaemia by altering glucose metabolism within the beta cells and decided to study glucokinase function because of its glucose sensing role and known abnormalities in $f a / f a$ rats. In this study we investigated the effects of ADX on glucose-induced insulin secretion, $\mathrm{MH}$ inhibitory action and glucose phosphorylation in isolated islets from lean and $f a / f a$ rats. Weanling lean and $f a / f a$ rats were adrenalectomized, then 2 weeks after surgery the glucokinase activity and insulin secretory response to glucose and $\mathrm{MH}$ were compared to sham-operated controls.

\section{Materials and methods}

Animals. Four-week-old female Zucker lean and obese rats were obtained from Charles River Laboratories (St. Constant, Quebec, Canada) and housed four animals per cage according to their phenotype. They were maintained in an artificially lit room with a 12-h dark, 12-h light cycle and a constant temperature of $22^{\circ} \mathrm{C}$ before and after they were either adrenalectomized or sham-operated at 5 weeks of age. They were fed commercial rodent laboratory chow 5001 (Purina, St. Louis, Mo., USA) and tap water ad libitum. After surgery they were also given a $\mathrm{NaCl} / g$ lucose solution $\left(154 \mathrm{mmol} \cdot \mathrm{H}^{-1} \mathrm{NaCl}\right.$ and 40 $\mathrm{mg} \cdot \mathrm{l}^{-1}$ glucose) to drink ad libitum.

$A D X$. Animals were fasted overnight and then weighed before surgery. They were anaesthetized i.p. using a mixture of sodium pentobarbital $\left(65 \mathrm{mg}^{-\mathrm{ml}^{-1}}\right.$ ) (MTC Pharmaceuticals,
Mississauga, Ont., Canada) and diazepam $\left(5 \mathrm{mg} \cdot \mathrm{ml}^{-1}\right)$ (Sabex Inc, Boucherville, Quebec, Canada) in $154 \mathrm{mmol} \cdot \mathrm{l}^{-1} \mathrm{NaCl}$ at a dose of $0.10-0.15 \mathrm{ml} \cdot 100 \mathrm{~g}$ body weight ${ }^{-1}$. Animals were either bilaterally adrenalectomized or sham-operated (and referred to as "control") using the ventral approach [22]. After 15 days solid food was removed from the cages overnight but the rats continued to have access to glucose $\mathrm{NaCl}$ solution and water. Before the pancreas was removed, the animals were weighed and $0.5-1.0-\mathrm{ml}$ blood samples were collected in heparinized tubes from the tail vein of freely moving conscious rats. Plasma was collected by centrifugation and stored at $-20^{\circ} \mathrm{C}$ for corticosterone and glucose determination (glucose oxidase method; Beckman Glucose Analyser II, Fullerton, Calif., USA). Animals that had no residual pieces of adrenal gland and with decreased serum corticosterone levels were considered to be completely adrenalectomized and were included in the analyses.

Islet isolation and culture. After blood was collected, the animals were anaesthetized i.p. with sodium pentobarbital (65 $\mathrm{mg} \cdot \mathrm{kg}$ body weight ${ }^{-1}$ ). Islets from $\mathrm{ADX}$ and control rats were isolated by a modification of the method of Van Der Vliet et al. [24] as described by Kibenge and Chan [17]. The islets were cultured overnight in Dulbecco's modified Eagle's medium (DMEM) (Gibco/BRL Canada Inc, Burlington, Ontario, Canada) supplemented with $1 \%$ antibiotic/antimycotic solution, $10 \mathrm{mmol} \cdot \mathrm{1}^{-1}$ 4-(2-hydroxyethyl)-1-piperazineethanesulphonic acid (Hepes) (Sigma Chemical Co, St. Louis, Mo., USA), $12.5 \mathrm{mmol} \cdot \mathrm{l}^{-1}$ glucose and $10 \%$ calf serum (Gibco/ BRL). By culturing overnight under standard conditions, immediate or short-term effects of the obese environment on islet function should be removed, leaving us able to study relatively persistent or long-term changes in insulin secretory regulation. Although culturing in various glucose conditions can result in changes in glucokinase function, conditions similar to those employed here in fact resulted in no significant changes in glucokinase kinetic parameters compared with freshly isolated islets, even when the culture period was as long as 7 days [14].

Insulin release and measurement. After overnight incubation, the culture medium was replaced with $1.0 \mathrm{ml}$ of fresh DMEM containing various glucose concentrations ranging from 0 to $25 \mathrm{mmol} \cdot \mathrm{l}^{-1}$ and $0.1 \%$ gelatin (Gibco/BRL). M (Sigma) (0.10-100 mmol $\left.\cdot 1^{-1}\right)$ was added to the islet samples containing 5.5-25.0 mmol $\cdot \mathrm{I}^{-1}$ glucose, which were then statically incubated for $90 \mathrm{~min}$ at $37^{\circ} \mathrm{C}\left(95 \%\right.$ air, $5 \% \mathrm{CO}_{2}$, saturated with water vapour). The supernatant was collected by aspiration and stored until assayed. To measure the total insulin content of the islets, the islet pellet was boiled in $3 \%$ acetic acid and then stored at $-20^{\circ} \mathrm{C}$ until assayed. Immunoreactive insulin was measured using a radioimmunoassay employing ${ }^{125} \mathrm{I}$-porcine insulin as the tracer and rat insulin as the standard, with a sensitivity range of $37.5-1200 \mathrm{pmol} \cdot \mathrm{l}^{-1}$. The insulin antiserum (Gp 01, raised in guinea pigs) was a gift from Dr. R.A. Pederson (University of British Columbia, Vancouver, B. C., Canada). Due to variability in pancreatic islet size, mostly from obese rats [6], insulin release was routinely expressed as a percent of total islet insulin content. The half-maximal glucose concentrations $\left(\mathrm{EC}_{50}\right)$ were calculated using Fig. P (version 6.0) software (Biosoft, Milltown, N.J., USA).

Corticosterone radioimmunoassay. Measurement of total serum corticosterone levels was carried out according to the kit manufacturer's manual (ICN Biomedical Inc., Montreal, Quebec, Canada). 
Table 1. Characteristics of ADX rats 2 weeks post-surgery

\begin{tabular}{|c|c|c|c|c|}
\hline \multirow[t]{2}{*}{ Parameter } & \multicolumn{4}{|l|}{ Treatment group } \\
\hline & ADX lean & Control lean & $\operatorname{ADX} f a / f a$ & Control $f a / f a$ \\
\hline$\overline{\text { Plasma corticosterone }\left(\mu \mathrm{g} \cdot \mathrm{ml}^{-1}\right)}$ & $0.08 \pm 0.02(15)^{\mathrm{b}}$ & $0.8 \pm 0.07(16)$ & $0.07 \pm 0.02(18)^{b}$ & $0.8 \pm 0.06(19)$ \\
\hline$\left(\mathrm{nmol} \cdot \mu \mathrm{g}\right.$ protein $\left.^{-1}\right)$ & $16.3 \pm 1.5(15)$ & $17.7 \pm 1.8(15)$ & $31.0 \pm 3.0(13)$ & $40.6 \pm 8.6(19)$ \\
\hline Plasma glucose $\left(\mathrm{mmol} \cdot \mathrm{l}^{-1}\right)$ & $6.1 \pm 0.3(10)$ & $7.1 \pm 0.9(10)$ & $7.0 \pm 0.5(11)$ & $7.5 \pm 0.7(13)$ \\
\hline Body weight $(\mathrm{g}) 5$ weeks & $85.9 \pm 2.1(15)$ & $89.4 \pm 2.0(16)$ & $134.5 \pm 3.6(18)^{a}$ & $139.8 \pm 4.8(19)^{\mathrm{a}}$ \\
\hline Body weight $(\mathrm{g}) 7$ weeks & $142.6 \pm 2.7(15)$ & $143.8 \pm 2.3(16)$ & $201.1 \pm 3.8(18)^{a, b}$ & $225.4 \pm 5.2(19)^{a}$ \\
\hline
\end{tabular}

Data are means \pm SEM of the number of animals $(n)$. Plasma hormone and glucose values were determined in plasma samples obtained from animals that had no access to solid food for $16 \mathrm{~h}$, but that continued to have access to water and the glucose/NaCl solution (see Methods).

${ }^{a} p<0.05$ compared with lean rats, unpaired $t$-test; ${ }^{\mathrm{b}} p<0.05$ compared with control rats of the same phenotype, unpaired $t$-test

Giucose phosphorylating activity. Two weeks after surgery, islets from control and ADX rats were isolated and cultured as described above. The following day, batches of $25-30$ islets were washed in glucokinase assay buffer containing 0.05 $\mathrm{mmol} \cdot \mathrm{1}^{-1}$ glucose. The assay buffer was Krebs-Ringer bicar-

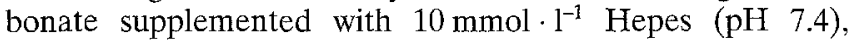
$5 \mathrm{mmol} \cdot \mathrm{l}^{-1} \mathrm{MgATP}, 10 \mathrm{mmol} \cdot \mathrm{l}^{-1} \mathrm{NaF}$, and glucose from $0.05-16 \mathrm{mmol} \cdot 1^{-1}$. After pelleting by centrifugation, the islets were re-suspended in $225 \mu$ l of assay buffer, containing glucose and other reagents as specified, and subjected to three freezethaw cycles at $-70^{\circ} \mathrm{C}$. At zero time, $\mathrm{D}-\left[\mathrm{U}^{14} \mathrm{C}\right] \mathrm{glucose}(250$ $\mathrm{mCi} \cdot \mathrm{mmol} \cdot \mathrm{1}^{-1}$; Amersham, Oakville, Ont., Canada) was added and the disrupted islets incubated for $20 \mathrm{~min}$ at $37^{\circ} \mathrm{C}$. The reaction was terminated by adding $30 \mu \mathrm{l} 0.25 \mathrm{~mol} \cdot \mathrm{1}^{-1}$ EDTA in $2 \mathrm{~mol} \cdot \mathrm{I}^{-1}$ glucose, and duplicate 60 - $\mu \mathrm{l}$ samples were subsequently spotted on diethylaminoethyl (DEAE) cellulose filters (Whatman DE-81; VWR Scientific, Toronto, Ont., Canada) that retain phosphoric esters [25]. The radioactivity retained on the washed and dried filters was counted by liquid scintigraphy. The protein content of the remaining sample was determined by the Lowry method, using bovine serum albumin as standard. Samples without islet tissue served as blank controls.

To determine hexokinase (ATP: D-glucose 6-phosphotransferase, EC 2.7.1.1) activity, glucose concentrations from $0.05-$ $0.50 \mathrm{mmol} \cdot \mathrm{I}^{-1}$ were used while $6.0-16.0 \mathrm{mmol} \cdot \mathrm{1}^{-1}$ glucose was used for glucokinase (ATP: D-glucose 6-phosphotransferase, EC 2.7.1.2) activity measurement. Velocities were calculated after correcting for specific activity and normalized by comparing to islet protein (Lowry method, Sigma). For glucokinase, values were corrected for hexokinase activity by subtracting $V_{\text {HEXOKINASE }}$ at $0.5 \mathrm{mmol} \cdot \mathrm{l}^{-1}$ glucose. Kinetic parameters were estimated from Eadie-Hofstee analysis of the data.

\section{Statistical analysis}

Data are expressed as mean \pm SEM and $(n)$ refers to the number of animals from which islets were isolated. Each data point is an average of duplicate samples from one animal. The insulin secretion data were analysed using two-way analysis of variance (general linear model) after arcsine transformation [26] of the actual percent data shown in the figures, when testing for interactions between $\mathrm{MH}$ concentrations and experimental variables such as age, phenotype, and ADX. One-way analysis of variance was used when comparing effects of different doses of test drugs within phenotypes using Minitab version 7.1 (Minitab Inc., State College, Pa., USA), which was followed by the Student-Newman-Keuls test. The unpaired t-test was used when comparing responses produced by the same treatment between phenotypes or between ADX and control rats of the same phenotype. Statistically significant differences $(p<0.05)$ in $\mathrm{K}_{\mathrm{m}}$ or $\mathrm{V}_{\max }$ of glucokinase were determined using the general linear model followed by Student-Newman-Keuls test. All results were considered significant at $p<0.05$.

\section{Results}

Characteristics of $A D X$ rats. Body weight, plasma corticosterone, and islet insulin content were compared in ADX and control rats (Table 1). Corticosterone levels were reduced by over $90 \%$ in both ADX lean and ADX $f a / f a$ rats. In control rats there was no phenotype difference in the plasma levels of corticosterone. The hormone levels in the control rats of both phenotypes were higher than those previously reported in normal rats [27], which might have been due to the stress of fasting and blood collection procedures.

ADX did not have any significant effect on the islet insulin content in either phenotype ( $p=0.656$ ), although ADX $f a / f a$ rats had $25 \%$ less pancreatic insulin content compared with control fa/fa rats when the data were expressed as insulin content per microgram islet protein. Obese ADX and control rats had more than two times more islet insulin content compared with the lean groups both before [17] and 2 weeks post-surgery. There was no effect of either phenotype or ADX on plasma glucose levels $(p=0.237)$. These glucose concentrations were higher than those measured after fasting because, although solid food had been removed, the animals still had access to the $\mathrm{NaCl} /$ glucose solution.

Obese rats weighed more than lean rats at ages 5 weeks (before ADX) and 7 weeks (15 days postsurgery). Comparison of both control and ADX groups at 5 and 7 weeks of age showed a significant effect due to both ADX and age. Within phenotype comparison showed that while ADX did not affect the weight gain pattern in lean rats, it slowed weight gain by $11 \%$ in $f a / f a$ rats $(p<0.05)$. 
Effects of $A D X$ on insulin secretion. The effects of increasing glucose concentration on insulin secretion from islets of ADX and control lean and $f a / f a$ rats were measured (Fig.1) and $\mathrm{EC}_{50}$ values were calculated. In lean ADX and control rats $(n=10$ each) there was no significant difference in the calculated $\mathrm{EC}_{50}\left(9.4 \pm 1.5 \mathrm{mmol} \cdot \mathrm{l}^{-1}\right.$ and $9.3 \pm 2.0 \mathrm{mmol} \cdot \mathrm{l}^{-1}$, respectively). For $\mathrm{ADX} f a / f a$ islets $(n=8)$ the $\mathrm{EC}_{50}$ for glucose was $10.6 \pm 2.7 \mathrm{mmol} \cdot \mathrm{r}^{-1}$, while in the islets of control $f a / f a$ rats $(n=8)$ an $\mathrm{EC}_{50}$ of $6.1 \pm$ $2.0 \mathrm{mmol} \cdot 1^{-1}$ was calculated $(p<0.05)$, indicating reduced glucose sensitivity in the ADX fa/fa islets. In order to facilitate comparisons with other studies, and to demonstrate the absolute magnitude of change in insulin secretion induced by ADX, estimates of absolute insulin secretory values per islet are given in Table 2. However, the wide range of values obtained, which is due to considerable variation in islet size and hence insulin content, precludes the use of absolute insulin concentrations to calculate $\mathrm{EC}_{50}$ values.

Glucose $\left(15 \mathrm{mmol} \cdot \mathrm{I}^{-1}\right)$-induced insulin secretion was measured in the absence or presence of $\mathrm{MH}$ $\left(0.10-30 \mathrm{mmol} \cdot \mathrm{l}^{-1}\right)$ as described in Methods. The amount of insulin released was affected by $\mathrm{MH}$ $(F \quad(5,126)=14.28 ; p<0.0001)$, phenotype $(\mathrm{F}(1$, $126)=7.50 ; \mathrm{p}=0.007), \quad \operatorname{ADX}(F(1,126)=33.64 ;$ $p<0.0001)$ and a phenotype/ADX interaction $(F(1$, $126)=49.55 ; p<0.0001)$. An MH concentration of $1.0 \mathrm{mmol} \cdot \mathrm{l}^{-1}$ or higher significantly reduced insulin secretion by pancreatic islets of lean ADX, lean control and ADX $f a / f a$ rats compared with their respective glucose controls ( $p<0.05$, Fig. 2). An effect of ADX on $\mathrm{MH}$ inhibition of glucose-induced insulin release was observed only in pancreatic islets of $\mathrm{fa} / \mathrm{fa}$ rats, where $\mathrm{MH}$ inhibited insulin secretion in a dosedependent manner (21.8-53.2\%). In isolated islets from control $\mathrm{fa} / \mathrm{fa}$ rats $\mathrm{MH}$ did not produce any significant reduction in glucose-induced insulin release $(p>0.05)$ (Fig. 2B). The $1.0 \mathrm{mmol} \cdot \mathrm{l}^{-1} \mathrm{MH}$ concentration produced only a $5 \%$ reduction in insulin secretion by pancreatic islets from control $\mathrm{fa} / \mathrm{fa}$ rats compared with a $48 \%$ reduction in control lean rats. Thus, ADX increased the sensitivity of the $f a / f a$ rat beta cells to $\mathrm{MH}$ inhibitory actions within 2 weeks of surgery.

Since $15 \mathrm{mmol} \cdot \mathrm{l}^{-1}$ glucose induces maximal stimulation of $f a / f a$ rat beta cells, we wanted to find out if $\mathrm{MH}$ would inhibit insulin secretion if sub-maximal glucose concentrations were used (Fig. 3). Glucoseinduced insulin release in the presence of 5.5 mmol $\cdot \mathrm{l}^{-1}$ glucose was not significantly $(p<0.05)$ inhibited with any $\mathrm{MH}$ concentrations used in isolated islets from either control or ADX rats of both phenotypes (data not shown). MH (1-100 mmol $\left.\cdot \mathrm{I}^{-1}\right)$ inhibitory action was varied in the presence of $8.3 \mathrm{mmol} \cdot \mathrm{l}^{-1}$ glucose. While there was no significant inhibition $(p>0.05)$ in either control and ADX obese rat islets, 30 and $100 \mathrm{mmol} \cdot \mathrm{I}^{-1} \mathrm{MH}$ produced a significant re-
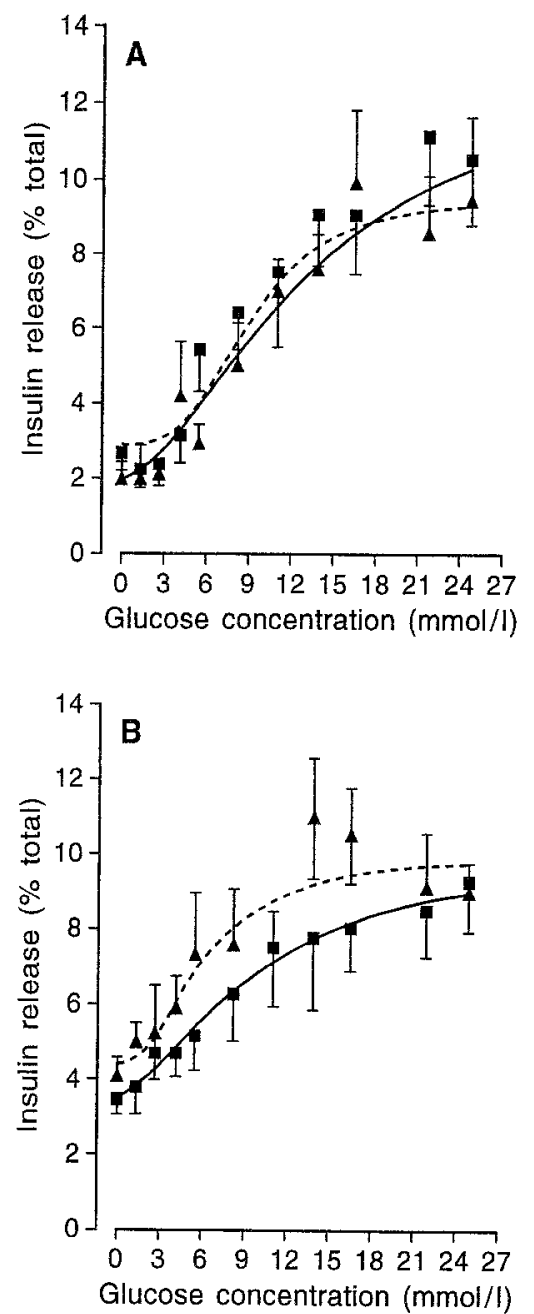

Fig. 1A, B. Effect of ADX on the insulin response (\% total islet insulin content in $90 \mathrm{~min})$ to glucose $\left(0-25.0 \mathrm{mmol} \cdot \mathrm{I}^{-1}\right)$ in isolated islets from $\mathrm{ADX}(\boldsymbol{O})$ and control $(\boldsymbol{\Delta})$ rats. $\mathbf{A}$ Lean rats $\left(n=7\right.$ for both); $\mathbf{B}$ obese rats $\left(n=8\right.$ for both). $\mathrm{EC}_{50}$ values reported in the text

duction $(p<0.05)$ in lean control rat islets, and $\mathrm{MH}$ concentrations of $3 \mathrm{mmol} / \mathrm{l}$ and higher significantly reduced insulin release in ADX lean islets in the presence of $8.3 \mathrm{mmol} \cdot \mathrm{l}^{-1}$ glucose. At a glucose level of $25.0 \mathrm{mmol} \cdot \mathrm{1}^{-1}, \mathrm{MH}$ concentrations of $3 \mathrm{mmol} \cdot \mathrm{l}^{-1}$ or higher produced significant reduction $(p<0.05)$ of insulin secretion from isolated islets of ADX lean and $f a / f a$, and control lean rats. Similar results were obtained in isolated islets of control lean, ADX lean and $f a / f a$ rats using a glucose concentration of $16.5 \mathrm{mmol} \cdot \mathrm{l}^{-1}$ There was no significant inhibition ( $p=0.726$ and $p=0.653$ for glucose concentrations of 16.5 and $25 \mathrm{mmol} \cdot \mathrm{l}^{-1}$, respectively) of insulin secretion in islets of control $\mathrm{fa} / \mathrm{fa}$ rats.

Effect of ADX on glucokinase activity. Glucose phosphorylating activity of disrupted islet preparations was measured 2 weeks after ADX or sham surgery. As shown in Figure 4, ADX significantly reduced the total phosphorylation of glucose (hexokinase + 
Table 2. Effect of ADX on glucose-stimulated absolute insulin secretion

\begin{tabular}{llllcr}
\hline $\begin{array}{l}\text { Glucose concen- } \\
\text { tration }\left(\mathrm{mmol} \cdot \mathrm{I}^{-1}\right)\end{array}$ & Insulin units & \multicolumn{2}{l}{ Treatment group } & & \\
\cline { 3 - 5 } & & ADX lean & ADX control & ADX fa/fa & Control fa/fa \\
\hline 2.8 & pmol $\cdot \mathrm{l}^{-1} \cdot$ islet $^{-1}$ & $163 \pm 47$ & $122 \pm 28$ & $720 \pm 128$ & $1139 \pm 460$ \\
& range & $(53.7-391)$ & $(9.4-229)$ & $(100-1149)$ & $(295-4273)$ \\
11.0 & pmol $\cdot \mathrm{I}^{-1} \cdot$ islet $^{-1}$ & $791 \pm 281$ & $406 \pm 75$ & $957 \pm 205$ & $1549 \pm 355$ \\
& range & $(44.9-2580)$ & $(126-643)$ & $(307-1626)$ & $(375-3968)$ \\
22.0 & pmol $\cdot \mathrm{l}^{-1} \cdot$ islet $^{-1}$ & $772 \pm 147$ & $502 \pm 133$ & $1355 \pm 308$ & $1757 \pm 487$ \\
& range & $(92.7-1497)$ & $(70.7-1086)$ & $(529-2391)$ & $(633-3968)$ \\
\hline
\end{tabular}

Data are the means \pm SEM or (range of values) for the number of experiments reported in Figure 1
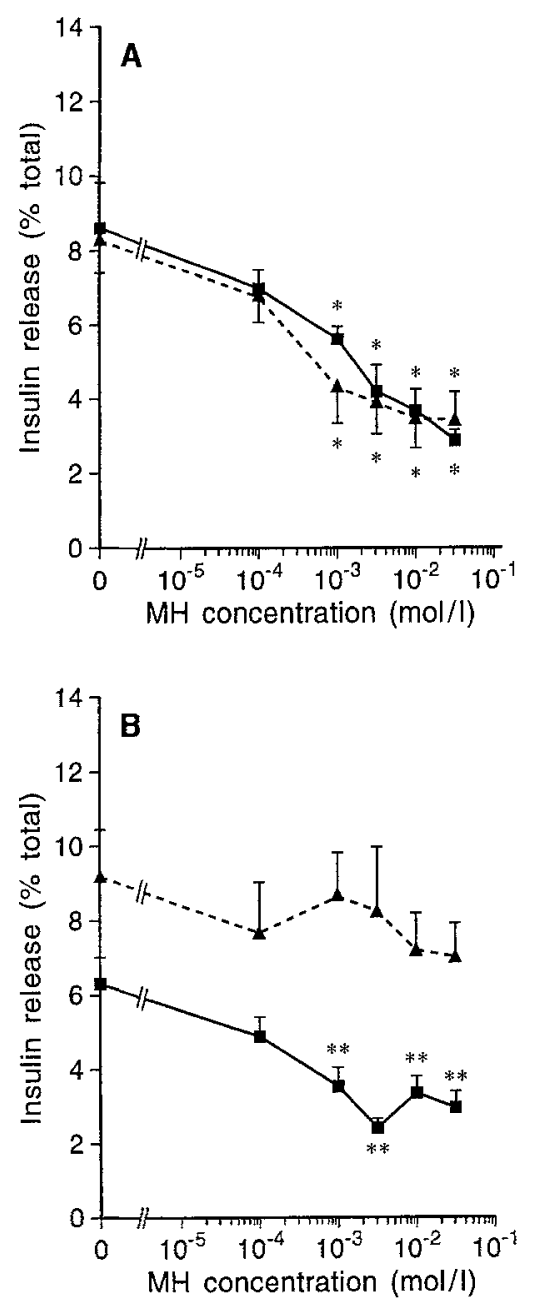

Fig. 2A, B. Effect of ADX on $\mathrm{MH}\left(0.1-100 \mathrm{mmol} \cdot \mathrm{l}^{-1}\right)$ action in isolated islets from $\operatorname{ADX}(\square)$ and control $(\mathbf{A})$ rats. A Lean control $(n=7)$ and $\operatorname{ADX}(n=6)$ islets; $\mathbf{B}$ obese control $(n=7)$ and $\operatorname{ADX}(n=6)$ islets. Insulin secretion was stimulated by $15 \mathrm{mmol} \cdot \mathrm{l}^{-1}$ glucose. $* p<0.05$ compared to the glucose control for each group. ${ }^{* *} p<0.05$ ADX compared to control $f a / f a$ rats

glucokinase) in islets of $f a / f a$ rats but had no significant effect in islets of lean rats. The reduced activity was due to altered glucokinase function, because ADX had no significant effect on hexokinase function in either phenotype (data not shown). Kinetic values obtained from Eadie-Hofstee analysis (Ta- ble 3) confirm that there was a trend to a leftward shift in the glucokinase $\mathrm{K}_{\mathrm{m}}$ of control fa/fa compared with lean rat islets, as found previously [11]. There was also a consistently lower $\mathrm{V}_{\text {max }}$ observed for $f a / f a$ islet glucokinase $(p<0.05)$. Adrenalectomy caused a twofold increase in the $\mathrm{K}_{\mathrm{m}}$ of $f a / f a$ islet glucokinase $(p<0.05)$ without altering the $\mathrm{V}_{\max }$, thereby reducing the glucose phosphorylation velocity for any given concentration of glucose (Fig. 4B). In lean rats, ADX increased the $V_{\max }$ of glucokinase (Table 3 ) but this did not result in any significant change in total phosphorylation of glucose in the physiological range (Fig.4A).

$\mathrm{MH}$ was previously shown to have no effect on glucose phosphorylation in islets from $f a / f a$ rats [11]. In this study, $\mathrm{MH}\left(10 \mathrm{mmol} \cdot \mathrm{l}^{-1}\right)$ caused a significant reduction in glucose phosphorylation in ADX but not control $f a / f a$ rat islets (Fig. 5B). MH inhibited glucokinase activity in both groups of lean rat islets (Fig.5A). In both lean rat islets and ADX fa/fa islets the inhibitory effect of $\mathrm{MH}$ was due to a twofold increase in the glucokinase $\mathrm{K}_{\mathrm{m}}$ (Table 3 ).

\section{Discussion}

Although ADX is known to reduce insulin secretion, its effects on specific beta-cell biochemical pathways have not been reported. In this study we investigated ADX effects on glucose response, glucokinase activity and $\mathrm{MH}$ inhibitory actions in isolated islets from both lean and $f a / f a$ rats. ADX reduced glucose sensitivity in the $\mathrm{ADX}$ fa/fa rat islets, increasing the $\mathrm{EC}_{50}$ from $6.1 \mathrm{mmol} \cdot \mathrm{l}^{-1}$ to $10.6 \mathrm{mmol} \cdot \mathrm{l}^{-1}$, comparable to control lean rat islets. Furthermore, sensitivity of $\mathrm{fa} / \mathrm{fa}$ rat islets to $\mathrm{MH}$ inhibition, which was reduced in all ages of rats tested [17], was nearly normalized by ADX. In intact adult lean rat islets, $10 \mathrm{mmol} \cdot \mathrm{l}^{-1}$ MH reduced glucose-induced insulin release by $45 \%$ but produced a non-significant reduction of $29 \%$ in the islets from fa/fa rats [17]. In this study $10 \mathrm{mmol} \cdot \mathrm{1}^{-1} \mathrm{MH}$ significantly reduced glucose-stimulated insulin release in isolated islets from $\mathrm{ADX}$ $f a / f a$, ADX lean and control lean rats by $48,57.6$ and $58.5 \%$, respectively but the same dose only produced 

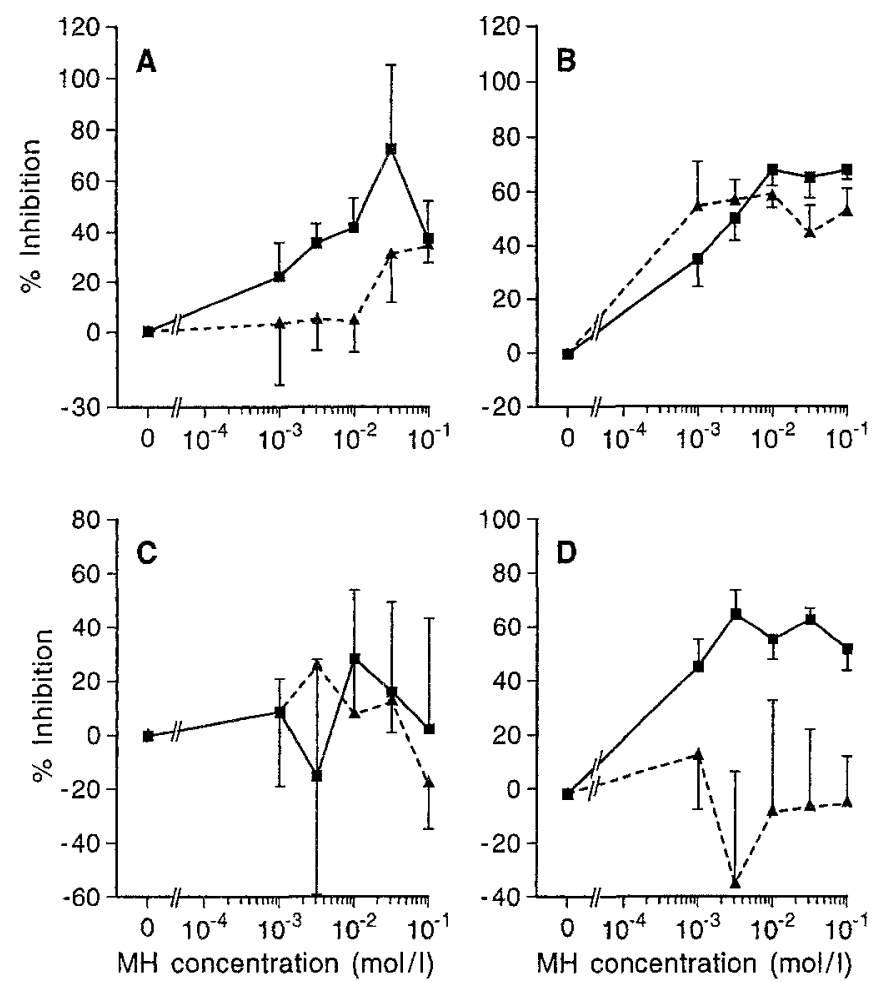

Fig. 3A-D. Comparison of the effect of $\mathrm{MH}$ action in isolated islets in the presence of glucose concentrations above and below the $\mathrm{EC}_{50}$. Insulin secretion from isolated islets in the presence of $\mathrm{MH}\left(0.10-100 \mathrm{mmol} \cdot \mathrm{l}^{-1}\right)$ was compared to $8.3\left(-\boldsymbol{A}_{-}\right)$, and $25.0(-\infty) \mathrm{mmol} \cdot \mathrm{I}^{-1}$ glucose-stimulated insulin secretion. A Lean control; $\mathbf{B}$ lean ADX; $\mathbf{C}$ obese control; $\mathbf{D}$ obese ADX. At least six islet preparations were used to generate each MH concentration response curve

a $23 \%$ reduction in $f a / f a$ control islets. The lowest $\mathrm{MH}$ concentration producing a significant effect was similar in islets from both ADX fa/fa, ADX lean, and control lean rats $\left(1.0 \mathrm{mmol} \cdot \mathrm{l}^{-1}\right)$ with glucose concentrations of $15 \mathrm{mmol} \cdot \mathrm{I}^{-1}$ or higher. This study clearly demonstrates that two specific beta-cell lesions related to glucose metabolism, insensitivity to MH and sensitivity to glucose, are dependent on the hypothalamo-pituitary-adrenal (HPA) axis in hyperinsulinaemic obese rats. Because $\mathrm{MH}$ competitively inhibits glucokinase it seems likely that the HPA axis is a modulator of glucokinase function in islets.
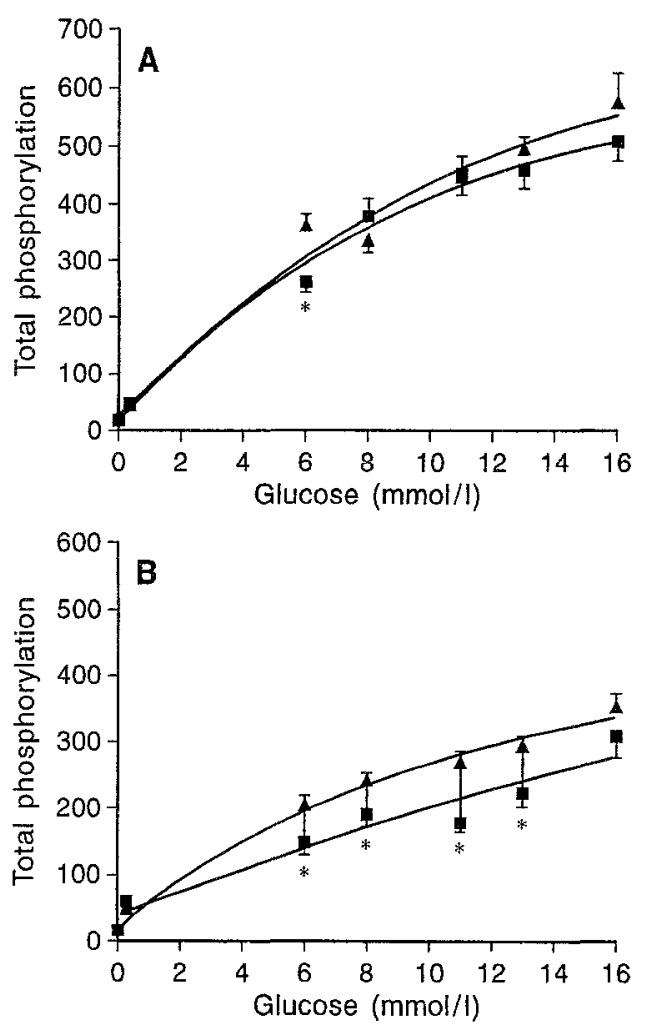

Fig. 4A, B. Effect of adrenalectomy (-口-) on total phosphorylation of glucose (pmol $\cdot \mu \mathrm{g}$ protein ${ }^{-1} \cdot \mathrm{h}^{-1}$ ) by hexokinase + glucokinase in (A) lean and (B) obese rat islets. Results are compared with data from sham-operated controls (-A-). The number of individual experiments from separate rat donors is as follows: control lean, 12; ADX lean, 11; control obese, 10; ADX obese, $6{ }^{*} p<0.05$ compared with control data

Our study of glucokinase kinetics supports the notion that normalization of both the glucose and $\mathrm{MH}$ sensitivity of the insulin secretory response occur because ADX modifies glucokinase function in $f a / f a$ rats. ADX $f a / f a$ rat islet glucokinase displayed a rightward shift in the $\mathrm{K}_{\mathrm{m}}$ for glucose, and a further increase in $\mathrm{K}_{\mathrm{m}}$ upon treatment of the islets with $\mathrm{MH}$, similar to results in lean rat islets. Results in control $\mathrm{fa} /$ $f a$ rat islets confirm our previous results of a leftward shift in the $\mathrm{K}_{\mathrm{m}}$ and insensitivity to $\mathrm{MH}$ compared with lean controls [11]. A role for glucokinase is further supported by earlier results indicating no differ-

Table 3. Effect of ADX on glucokinase kinetic parameters

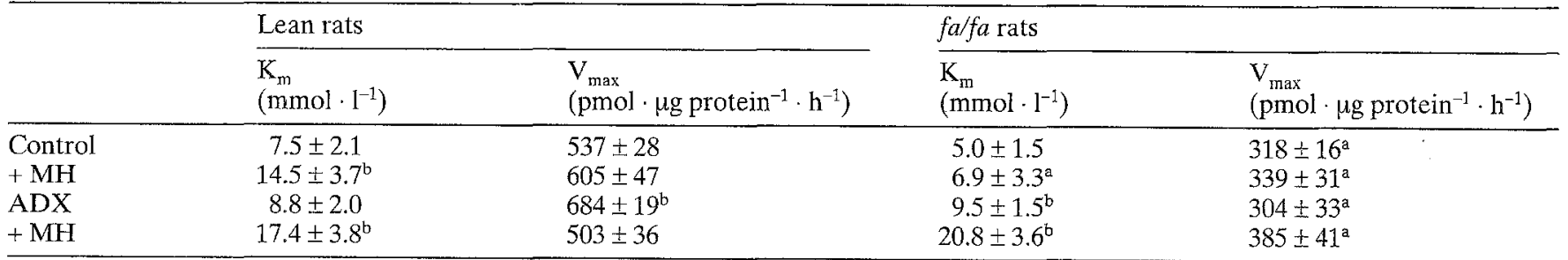

Kinetic values were calculated using Eadie-Hofstee analysis ( $\mathrm{V} v \mathrm{Vs} / \mathrm{S}$ ) after correcting for hexokinase activity at $0.5 \mathrm{mmol} \cdot \mathrm{l}^{-1}$ glucose. Data are means \pm SEM for the number of experiments reported in Figure 5 .

${ }^{a} p<0.05$ compared with lean rats;

${ }^{b} p<0.05$ compared with phenotype-matched controls 

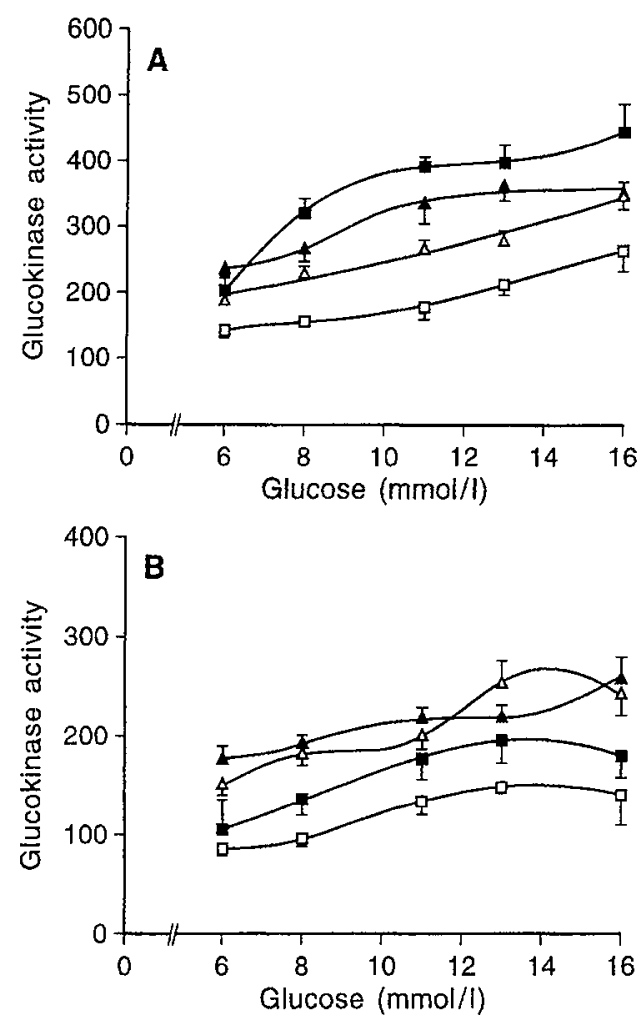

Fig. 5A, B. Effect of ADX on glucokinase activity (pmol $\mu \mathrm{g} \cdot$ protein $^{-1} \cdot \mathrm{h}^{-1}$ ) in the presence (open symbols) or absence (closed symbols) of $\mathrm{MH}$. $\mathbf{A}$ control lean $(\boldsymbol{\Lambda}, \Delta, n=12)$ and ADX lean ( $\square, \square, n=11$ ) rat islets. $M H$ significantly $(p<0.05)$ inhibited glucokinase activity in both groups of lean rat islets. B Control obese $(\boldsymbol{A}, \triangle, n=8)$ and ADX obese $(\square$, $\square, n=6)$ rat islets. $\mathrm{MH}$ significantly $(p<0.05)$ inhibited glucokinase activity only in ADX obese rat islets (Table 3)

ence in sensitivity to non-glucidic secretagogues including $\alpha$-ketoisocaproic acid, $\mathrm{L}$-arginine, and quinine [9]. Glucokinase is a low-affinity glucose-phosphorylating enzyme found only in liver cells and pancreatic islet beta cells [10]. While the activities of both liver and pancreatic glucokinase isoforms are similar, gene expression of the isoforms is regulated differently because of tissue-specific promoter regions of the gene [28]. Known regulators of islet beta-cell glucokinase expression and activity include glucose [13,29], exercise [30], and starvation [12]. The data obtained in the current study are evidence that pancreatic glucokinase activity is also regulated by the HPA axis but does not indicate whether glucocorticoids directly modulate glucokinase or exert their effects via their influence on the anterior pituitary or hypothalamic nuclei. Results of studies investigating direct glucocorticoid action on insulin secretion or biosynthesis, and on pancreatic glucokinase activity are not conclusive [31-34]. However, glucocorticoids may increase pancreatic islet beta-cell glucokinase activity indirectly either by increasing glucose production by the liver or by acting through the HPA axis $[35,36]$.

Developmental studies show that glucokinase mRNA is present in pancreatic tissues of 2-day-old rat pups [37]. Glucocorticoids are detected at very low levels in 6-12-day-old rats, but increase considerably by the end of the second week reaching peak levels by 24 days of age in rats [38]. It is during this period, in 17-21-day-old fa/fa rats, that enhanced parasympathetic nervous system potentiation of glucose-induced insulin secretion in $f a / f a$ rats was observed [5]. ADX performed in 18-day-old fa/fa rats abolished this parasympathetic nervous system effect in the $f a / f a$ rat pancreas but it could be restored by corticosterone replacement within $24 \mathrm{~h}$ [20]. Increased parasympathetic nervous system stimulation of glucose-induced insulin release in the $f a / f a$ pancreatic tissue was even observed in 5-day-old pre-obese pups [3]. Although not supported by experimentation to date, one could speculate that glucokinase activity is increased in $f a / f a$ pups even at this early stage. The increased glucokinase activity is probably masked by the high-fat diet during suckling.

ADX or infusion of corticotrophin releasing hormone (CRH) into cerebral ventricles results in body weight loss, reduced food intake, increased sympathetic nervous activity in the periphery and reduced insulin secretion in $f a / f a$ rats and other obese rodents [39-42]. These observations have led to the hypothesis that the actions of corticosterone in obesity are due to an inhibitory action on central $\mathrm{CRH}$, especially in the hypothalamic nuclei that are involved in the integration of both endocrine and autonomic nervous system function in relation to energy balance $[43$, 44]. Specifically in the $f a / f a$ rat, it was concluded that lower CRH tone in the hypothalamus is due to defects in regulation of the HPA axis proximal to the region of the CRH system that mediates feedback inhibition of corticosterone secretion because the pituitaryadrenal axis had normal response to a CRH challenge [44]. It then follows that the beta-cell biochemical defects observed in 5-week-old $f a / f a$ rats might be under the control of an already abnormally-regulated HPA axis [45]. How increasing hypothalamic CRH levels modulate peripheral events such as insulin secretion is not precisely known; however, ADX appears to increase sympathetic outflow relative to parasympathetic outflow by a CRH-mediated mechanism [46, 47]. Thus, it is tantalizing to speculate that a deficient sympathetic nervous system in the developing $f a / f a$ rat pancreas causes reversible changes in glucokinase function. This idea is consistent with the data showing that exercise, which also alters sympathetic outflow, can decrease glucokinase activity [30].

In this study, ADX did not cause the body weight of $f a / f a$ rats to return to the same level as that of lean rats. These results agree with those of other investigators showing that ADX performed at 5 weeks or later does not completely normalize $f a / f a$ rat body weight to that of the lean rats, but reduces the rate of body fat accumulation in the ADX $f a / f a$ rats $[23,48]$. Nor did ADX affect pancreatic islet insulin content 
in either lean or $f a / f a$ rats. These results concur with those of Fiedorek and Permutt [36] where ADX did not affect proinsulin mRNA levels in $20 \%$ sucrosefed ADX Sprague-Dawley rats, but did reduce proinsulin mRNA in fasted or fed ADX rats without sucrose supplement. In our study both ADX and control rats had unlimited access to $\mathrm{NaCl} /$ glucose solution throughout the 15 days post-surgery. Because the control $f a / f a$ rats in this study gained more weight than the ADX $f a / f a$ rats we therefore reached the same conclusion, i.e. that glucocorticoids are not essential for insulin synthesis if the animals have adequate plasma glucose.

In conclusion, changes in pancreatic glucokinase activity are likely to contribute to the development of hyperinsulinaemia in the $f a / f a$ rat. The development of this lesion in the $\mathrm{MH}$ response is dependent on the presence of an intact HPA axis, and ADX, in this study, restored pancreatic islet MH sensitivity in isolated islets of $f a / f a$ rats.

Acknowledgements. The technical assistance of Ms. R. MacPhail and Ms. K. Mitton is greatly appreciated. This study was supported by grants to Dr. Chan from the Canadian Diabetes Association in honour of Mildred Paynter and the Medical Research Council of Canada.

\section{References}

1. Bray GA, York DA (1979) Hypothalamic and genetic obesity in experimental animals: an autonomic and endocrine hypothesis. Physiol Rev 59: 719-809

2. Bray GA (1977) The Zucker-fatty rat: a review. Fed Proc 36: $148-153$

3. Atef N, Brulé, C, Bihoreau M-T, Ktorza A, Picon L, Pénicaud L (1991) Enhanced insulin secretory response to acetylcholine by perifused pancreas of 5-day old pre-obese Zucker rats. Endocrinology 129: 2219-2223

4. Chan CB, Pederson RA, Buchan AMJ, Tubesing KB, Brown JC (1985) Gastric inhibitory polypeptide and hyperinsulinaemia in the Zucker $(f a / f a)$ rat: a developmental study. Int J Obes 9: 137-146

5. Rohner-Jeanrenaud F, Hochstrasser A-C, Jeanrenaud B (1983) Hyperinsulinaemia of pre-obese and obese $\mathrm{fa} / \mathrm{fa}$ rats is partly vagus-mediated. Am J Physiol 244:E317-E322

6. Chan CB, Pederson RA, Buchan AMJ, Tubesing KB, Brown JC (1984) Gastric inhibitory polypeptide (GIP) and insulin release in the obese Zucker rat. Diabetes 33: 536-542

7. Kuffert A, Stern JS, Curry DL (1988) Pancreatic hypersensitivity to glucose by young obese Zucker rats $(\mathrm{fa} / \mathrm{fa}$ ). Metab Clin Exp 37: 952-957

8. Curry DL, Stern JS (1985) Dynamics of insulin hypersecretion by obese Zucker rats. Metab Clin Exp 34: 791--796

9. Chan CB, MacPhail RM, Mitton K (1993) Evidence for defective glucose sensing by islets of $f a / f a$ obese Zucker rats. Can J Physiol Pharmacol 71: 34-39

10. Matschinsky FM (1990) Glucokinase as glucose sensor and metabolic signal in pancreatic B-cells and hepatocytes. Diabetes 39: 647-652

11. Chan CB (1993) Glucokinase activity in isolated islets from obese fa/fa Zucker rats. Biochem J 295: 673-677
12. Burch PT, Trus MD, Berner DK, Leontire A, Zawalich KC, Matschinsky FM (1981) Adaptation of glycolytic enzymes: glucose use and insulin release in rat pancreatic islets during fasting and refeeding. Diabetes 30: 923-928

13. Liang Y, Najafi H, Matschinsky FM (1990) Glucose regulates glucokinase activity in cultured islets from rat pancreas. J Biol Chem 265: 16863-16866

14. Liang Y, Najafi H, Smith RM et al. (1992) Concordant glucose induction of glucokinase, glucose usage, and glucosestimulated insulin release in pancreatic islets maintained in organ culture. Diabetes 41: 792-806

15. Zucker LM, Antoniades HN (1972) Insulin and obesity in the Zucker genetically obese rat "fatty". Endocrinology 90: $1320-1330$

16. Zawalich WS (1979) Intermediary metabolism and insulin secretion from isolated rat islets of Langerhans. Diabetes 28: $252-260$

17. Kibenge MT, Chan CB (1995) Identification of biochemical defects in pancreatic islets of $f a / f a$ rats: a developmental study. Obes Res 3: 171-178

18. Timmers KI, Voyles NR, Recant L (1992) Genetically obese rats with (SHR/N-cp) and without diabetes (LA/Ncp) share abnormal islet response to glucose. Metabolism 41: 1125-1133

19. Fletcher JM (1986) Effects of adrenalectomy before weaning and short- or long-term glucocorticoid administration on the genetically obese Zucker rat. Biochem J 238: 459463

20. Fletcher JM, McKenzie N (1988) The parasympathetic system and glucocorticoid-mediated hyperinsulinaemia in genetically obese $f a / f a$ Zucker rats. Endocrinology 118: 87-92

21. Yukimura Y, Bray GA, Wolfsen AR (1978) Some effects of adrenalectomy in fatty rats. Endocrinology 103: 1924-1928

22. Castonguay TW, Dallman MF, Stern J (1986) Some metabolic and behaviour effects of adrenalectomy on obese Zucker rats. Am J Physiol 251:R923-R933

23. Turkenkopf IJ, Kava RA, Feldweg A, Horowitz C, Greenwood MR, Johnson PR (1991) Zucker and Wistar diabetic fatty rats show different response to adrenalectomy. Am J Physiol 261:R912-R919

24. Van Der Vliet JA, Meloche RM, Field MJ, Chen D, Kaufman DB, Sutherland DER (1988) Pancreatic islet isolation in rats with ductal collagenase distension, stationary digestion and dextran separation. Transplantation 45: 493495

25. Bedoya FJ, Ramirez R, Arilla E, Goberna R (1984) Effect of 2-bromostearate on glucose-phosphorylating activities and the dynamics of insulin secretion in islets of Langerhans during fasting. Diabetes 33: 858-863

26. Zar JH (1974) Biostatistical analysis. Prentice-Hall, Englewoods Cliffs, N.J.

27. Shargill NS, Al-Baker I, York DA (1987) Normal levels of serum corticosterone and hepatic glucocorticoid receptors in obese $(f a / f a)$ rats. Biosci Rep 7: 843--851

28. Iynedjian PB, Pilot P-R, Nouspikel Tet al. (1989) Differential expression and regulation of glucokinase gene in liver and islets of Langerhans. Proc Natl Acad Sci USA 86: $7838-7842$

29. Bedoya FJ, Matschinsky FM, Shimizu T, O’Neil JJ, Appel MC (1986) Differential regulation of glucokinase activity in pancreatic islets and liver of the rat. J Biol Chem 23: 10760-10764

30. Koranyi LI, Bourey RE, Slentz CA, Holloszy JO, Permutt MA (1991) Coordinate reduction of rat pancreatic islet glucokinase and proinsulin mRNA by exercise training. Diabetes 40: 401-404 
31. Chan CB, Lejeune J (1992) Reduced sensitivity to dexamethasone of pancreatic islets from obese $(f a / f a)$ rats. Can J Physiol Pharmacol 70: 1518-1522

32. Fernandez-Mejia C, Davidson MB (1992) Regulation of glucokinase and proinsulin gene expression and insulin secretion in RIN-m5F cells by dexamethasone, retinoic acid and thyroid hormone. Endocrinology 130: 1660-1668

33. Philippe J, Giordno E, Gjinovci A, Meda P (1992) Cyclic adenosine monophosphate prevents the glucocorticoidmediated inhibition of insulin gene expression in rodent islet cells. J Clin Invest 90: 2228-2233

34. Narkewicz MR, Iynedjian PB, Ferre P, Girard J (1990) Insulin and triiodothyronine induce glucokinase mRNA in primary culture of neonatal rat hepatocytes. Biochem $\mathrm{J}$ 271: 585-589

35. Koranyi LI, Bourey R, Turk J, Mueckler M, Permutt MA (1992) Differential expression of rat pancreatic islet betacell glucose transporter (GLUT 2), proinsulin and islet amyloid polypeptide gene after prolonged fasting, insulininduced hypoglycaemia and dexamethasone treatment. Diabetologia 35: 1125-1132

36. Fiedoreck FT, Permutt MA (1989) Proinsulin mRNA levels in fasting and fed $\mathrm{ADX}$ rats: evidence for indirect effect of glucocorticoids. Am J Physiol 256:E303-E308

37. Tiedge M, Lenzen S (1993) Differential regulation of glucokinase and GLUT-2 glucose transporter gene expression in the pancreas and liver from neonatal and 16 day old rats. Biochem Mol Biol Int 29: 161-166

38. Henning SJ (1978) Plasma concentrations of total and free corticosterone during development in the rat. Am J Physiol 235:E451-E456

39. Brown MR, Fisher LA (1985) Corticotropin-releasing factor: effects on autonomic nervous system and visceral systems. Fed Proc 44: 243-248
40. Arase K, York DA, Shimazu H, Shargill NS, Bray GA (1988) Effects of corticotropin releasing factor on food intake and brown adipose tissue thermogenesis in rats. Am J Physiol 255:E255-E259

41. Arase K, Shargill NS, Bray GA (1989) Effects of intraventricular infusion of corticotropin-releasing factor on VHM lesioned obese rats. Am J Physiol 256:R751-R756

42. Holt SJ, York DA (1989) The effects of adrenalectomy, corticotropin releasing factor and vasopressin on the sympathetic firing rate of nerves to interscapular brown adipose tissue in Zucker rat. Physiol Behav 45: 1123-1129

43. Bestetti GE, Abramo F, Guillaume-Gentil C, Rohner-Jeanrenaud F, Jeanrenaud B, Rossi GL (1990) Changes in the hypothalamo pituitary-adrenal axis of genetically obese fa/fa rats: a structural, immunocytochemical, and morphometrical study. Endocrinology 126: 1880-1887

44. Plotsky PM, Thrivikraman KV, Watts AG (1992) Hypothalamic-pituitary-adrenal axis function in the Zucker obese rat. Endocrinology 130: 1931-1941

45. Fletcher JM, Haggarty P, Wahle KWJ, Reeds PJ (1986) Hormonal studies of young lean and obese Zucker rats. Horm Metabol Res 18: 290-295

46. Holt SJ, York DA (1982) The effect of adrenalectomy on GDP binding to brown adipose tissue mitochondria of obese rats. Biochem J 208: 819-822

47. Holt SJ, Rothwell NJ, Stock MJ, York DA (1988) Changes in energy balance, thermogenesis and brown adipose tissue activity following hypophysectomy in obese Zucker rats. Am J Physiol 254:E162--E166

48. Yukimura Y, Bray GA (1978) Effects of adrenalectomy on body weight and the size and number of fat cells in the Zucker (fatty) rats. Endocr Res Commun 5: 189-198 